\title{
Effect of pH and Irradiation Power in the Synthesis of Gold Nanoparticles by using Binahong (Anredera cordifolia) Leaves Extract
}

\author{
FOLIATINI ${ }^{1}$ and NURDIANI ${ }^{2 *}$ \\ 1'Department of Chemistry, Analysis Polytechnic of AKA Bogor, Bogor 16154, Indonesia. \\ ${ }^{2}$ Department of Industrial Waste Treatment, Polytechnic of AKA Bogor, Bogor 16154, Indonesia. \\ *Corresponding author E-mail: nurdiani97@gmail.com \\ http://dx.doi.org/10.13005/ojc/370230
}

(Received: February 23, 2021; Accepted: March 10, 2021)

\begin{abstract}
Au nanoparticles have been successfully synthesized using extract of binahong (Anredera cordifolia) leaves at various $\mathrm{pH}$, irradiation power and irradiation time. The synthesis was conducted using microwave oven for some minutes, at certain adjusted experimental condition. $\mathrm{pH}$ of solution was varied from $2-10$, irradiation power was adjusted in the range of $30 \%-100 \%$ of total power of $800 \mathrm{~W}$, and iiradiation time was studied in the range of $30-120$ second. The experimental results showed at low $\mathrm{pH}$, the nonspherical particle was more commonly formed. The stabilization of particles took place more effectively at the higher $\mathrm{pH}$. At low pH, the nanoparticles were below 50 $\mathrm{nm}$ in size and were in form of triangle, rod, rhombic, cubic, or truncated form of these shapes. UV-Vis spectra also indicated that both microwave irradiation power and time significantly affect the morphology of particles. The research provide clear explanation about the effect of the $\mathrm{pH}$ and irradiation time over the AuNP synthesis by using greener method, which can be further studied in optimizing experimental parameters for conducting industrial scale synthesis.
\end{abstract}

Keywords: Gold nanoparticles, Binahong leaves extract, pH, Irradiation power, Irradiation time.

\section{INTRODUCTION}

Synthesis of gold nanoparticles may follow many kinds of mechanism, such as templateassisted synthesis ${ }^{1,2}$, seed-mediated synthesis ${ }^{3,4}$, or high frequency energy-assisted synthesis ${ }^{5,6}$. Even though those mechanisms may yield nanoparticles with controlled morphology, however, those methods require many steps in the preparation and some of them may need high $\operatorname{cost}^{7,8}$. Moreover, the need of chemicals as reducing agents in those techniques may potential in creating toxic waste, which is harmful to the environment.

Many researchers have proposed alternative methods in creating nanoparticles by facile, simple, low cost, green one pot synthesis by using extract of part of several plants ${ }^{9,10,11}$.

Several extract from plants have been studied for the purpose, such as, mentha and pelargonium plant ${ }^{19}$., Citrus maxima fruit ${ }^{13}$., Cannabis

This is an Open Access article licensed under a Creative Commons license: Attribution 4.0 International (CC- BY). Published by Oriental Scientific Publishing Company @ 2018

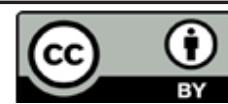


sativa stem ${ }^{14}$., Annona muricata leaf ${ }^{15}$., Silybum marianum $^{16}$., star fruit $\left(\right.$ Averrhoa bilimbI) ${ }^{17}$.

Binahong (Anredera cordifolia) is one of tropical plant indigeneous from Indonesia and the leaves is usually used as herbal medicine. Previous study reported abundant flavonoid content of the binahong (Anredera cordifolia) leaves ${ }^{18}$. Thus the leaves are potentially source of reducing agent for green synthesis of metal nanoparticles. Foliatini and Nurdiani ${ }^{19}$. have reported that the binahong leaves have ability to be reducing agent in the synthesis of Au nanoparticles. However, since the flavonoid and several phytochemicals present in the leaves may play significant role in controlling the morphology of the as-formed nanoparticles, their effect on the structure may become very important to be examined. Most of phytochemicals from plants have functional groups which may render their structure when they present in the acidic or basic solution. Based on the fact, the synthesis of nanoparticles at various $\mathrm{pH}$ must be conducted to evaluate the effect of acidity of the medium on the optical and morphological characteristic of the nanoparticles. Several other factors which may affect the effectivity of the Au nanoparticle preparation, including irradiation power and reaction time, are also important to be studied comprehensively. The effectivity of the synthesis used here was in term of its success in generating Au nanoparticles with certain morphological and optical properties for a reasonable reaction time. Irradiation power is related to the energy required for nucleation and growth of particles ${ }^{20,21}$. thus, has great importance in controlling morphology and polydispersity of particles. $\mathrm{pH}$ is a such an experimental variable that contribute to the size, shape, concentration ${ }^{22}$ and also the stability of the as-formed particles ${ }^{23}$.

Most of studies about synthesis using natural resources (extracts from plants) had been focused on the synthesis of spherical particles. However, various biomedical applications, including bioimaging, sensitive detection for disease marker, photothermal/photodynamic therapy of pathogenic microorganisms or cancer cells, need special optical properties of Au nanoparticles, which can be fulfilled by anisotropic (nonspherical) nanoparticles ${ }^{24,25}$. Thus, this research opened a new potential route for obtaining this kind of particles.
In this study, we conducted the synthesis of Au nanoparticles using binahong leaves extract at various $\mathrm{pH}$, irradiation power and reaction time. The experimental results revealed the role of each variables in this synthesis and provided the optimum condition for the effective synthesis of $\mathrm{Au}$ nanoparticles.

\section{EXPERIMENTAL}

The Binahong (Anredera cordifolia) was harvested from local area in Bogor, West Java. Chemical reagent such as double-distilled water, hydrochloric acid, sodium hydroxide, were purchased from Merck. All chemicals used in this synthesis were of analytical grade. The Binahong (Anredera cordifolia) leaves were extracted using aquabidest by cutting the leaves in small pieces and boiling it in double-distilled water using magnetic stirrrer for 20 minute. The bottom-up synthesis of anisotropic gold nanoparticles was selected using extract of binahong (Anredera cordifolia) leaves as reducing agent and stabilizer and the heating process was accomplished by microwave irradiation.

\section{Sample preparation}

The synthesis was conducted using procedures reported in the previous study ${ }^{19}$. Briefly, the preparation of binahong (Anredera cordifolia) leaves samples begins with the selection of fresh $50 \mathrm{~g}$ binahong (Anredera cordifolia) leaves and cut into small pieces and then boil with $100 \mathrm{~mL}$ aquabidest for $20 \mathrm{~min}$ at $70^{\circ} \mathrm{C}$. The extract obtained is then filtered. $10 \mathrm{~mL}$ volume of $0.5 \mathrm{mM} \mathrm{HAuCl}_{4}$ was poured in beaker glass and added by $10 \mathrm{~mL}$ extract binahong leaves until a total volume of $20 \mathrm{~mL}$. The beaker glass was put in the microwave oven and heated for 2-3 min with variations in radiation power. The change of solution color from yellow to red or purple/magenta indicated that the nanoparticles were formed. The colloidal solution of the nanoparticles were sentrifuged at $3000 \mathrm{rpm}$ for 30 minutes. The optimum concentration of $\mathrm{AuCl}^{-}$and extract were obtained from previous study ${ }^{19}$. The $\mathrm{pH}$ of the synthesis was varied as 2, 6 and 10. The irradiation power of microwave was varied as $30 \%$, $50 \%, 80 \%$ and $100 \%$ of total power of $800 \mathrm{~W}$. After the purification process, the gold nanoparticles were subjected to the characterization procedures.

\section{Characterization procedures}

Spectrum of surface plasmon resonance 
(SPR) of the Au nanoparticles colloidal solution was monitored using UV-Vis spectrophotometer (Shimadzu) to evaluate the peak in the wavelength range from 350 to $800 \mathrm{~nm}$. Fourier Transform Infrared Spectroscopy (FTIR) spectrometer (Bruker) was utilized to determine the functional groups presented in the biomoleculecapped nanoparticles. The FTIR spectrum was scanned in the wavenumber range from 4000 to $400 \mathrm{~cm}^{-1}$. Themorphology of the nanoparticles was characterized by transmission electron microscopy (TEM, JEOL) at $120 \mathrm{kV}$ accelerating voltage.

\section{RESULTS AND DISCUSSION}

Previous study reported that methanolic extract of binahong leaves contain flavonoids, saponins, sterol/triterpenes, and coumarin ${ }^{26}$. Even though the different extracting agent may give different phytochemical composition, the polarity between water and methanol were similar thus it can be predicted that the phytochemicals extracted by both two solvents have similar composition. To confirm the presence of these compounds in the extract and in the as-prepared nanocomposites, we characterized the nanocomposited using FTIR techniques. FTIR has been proved as an effective tool to provide information of functional groups present in the substances.

FTIR characterization of as-synthesized gold nanoparticles revealed several functional groups, from their peaks, i.e. $3518 \mathrm{~cm}^{-1}, 3155$ $\mathrm{cm}^{-1}, 1617 \mathrm{~cm}^{-1}$ and $790 \mathrm{~cm}^{-1}$. Peak at $3518 \mathrm{~cm}^{-1}$ corresponds to $-\mathrm{OH}$ groups. Carbonyl functional groups were shown by peak at $1617 \mathrm{~cm}^{-1}$. This peak have red-shifted to much lower wavenumber, indicated that these functional groups attached to a certain groups which pull electron density away from $\mathrm{C}=\mathrm{O}$ double bonds. This result indicated the presence of $-\mathrm{COOH}$ - groups in the nanocomposite structure (Figure 1).

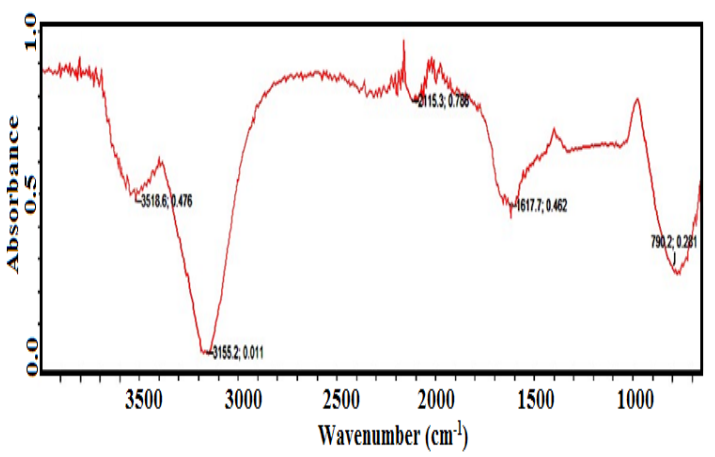

Fig. 1. FTIR spectrum of gold nanoparticles synthesized by binahong (Anredera cordifolia) leaves extract

\section{Effect of $\mathrm{pH}$}

The effect of $\mathrm{pH}$ was studied at $\mathrm{AuCl}_{4}$ concentration of $0,4 \mathrm{mM}$ using extract from first boiling. The UV-Vis spectra (Fig. 2) showed the typical curves at maximum wavelength of $480-500 \mathrm{~nm}$, associated to the SPR band. The absorbance of each $\mathrm{pH}$ was different, but differences in the absorbance values at those different peak cannot be regarded as a different concentration in a linear relationship, since the different maximum wavelength related to the different mechanism. Previous study reported that $\mathrm{pH}$ of the synthesis medium had a significant effect on the resulting concentration of the nanoparticles. In that study, the Au nanoparticles concentration varied proportionally a function of the $\mathrm{pH}^{22}$.

Jiang et al., ${ }^{27}$ have reported that $\mathrm{pH}$ may greatly affect the particle morphology, when the stabilizing agent have certain groups which can be converted to other species as $\mathrm{pH}$ was varied, such as carboxyl groups $(-\mathrm{COOH})$. This phenomenon related to the nucleation and growth rate, which were influenced by $\mathrm{pH}$ change.

The similar phenomenon was also found in the synthesis of $\mathrm{Ag}$ nanoparticles ${ }^{23}$. The solution $\mathrm{pH}$ modifies the surface charge of the nanoparticles, especially for carboxyl or amino-bearing surface groups. As a result, the nanoparticles behavior varied in acidic and alkaline conditions. Increasing $\mathrm{pH}$ resulting in lower aggregation, leading to decreased of particle size and increased of particle stability. At low $\mathrm{pH}$, protonation occurs effectively, thus there are large numbers of hydrogen bonds formed in this condition. These hydrogen bonds caused the biomolecules get closer each other, and more reducing groups interacting with $\mathrm{Au}$ (III) which trapped in the gap between biomolecules. Therefore the reduction reaction takes place fast enough. If this is not balanced with steric stabilization, the nanoparticles will grow uncontrollably, forming large particles.

Figure 2 (left) showed that at higher $\mathrm{pH}$, the wavelength of the SPR peaks were blue-shifted to the lower value. At low $\mathrm{pH}$, the larger amount of $\mathrm{H}^{+}$were available in the solution to protonate the -COO- groups, creating more $-\mathrm{COOH}$ form of carboxyl group, leading to the larger amount of hydrogen bonds between $-\mathrm{COOH}$ groups. These weak intermolecular interaction played important role in the aggregation process of the particles. As the $\mathrm{pH}$ increases, the amount of $\mathrm{H}^{+}$decreases, thus, larger amount of carboxyl groups converted into anionic form (-COO-). The anionic species tends to create abundant electrostatic repulsion between biomolecules, resulting in lower probability 
of aggregation (Fig. 2). It can be concluded that at higher $\mathrm{pH}$, the particle size decreases, which was similar to the result of previous study.
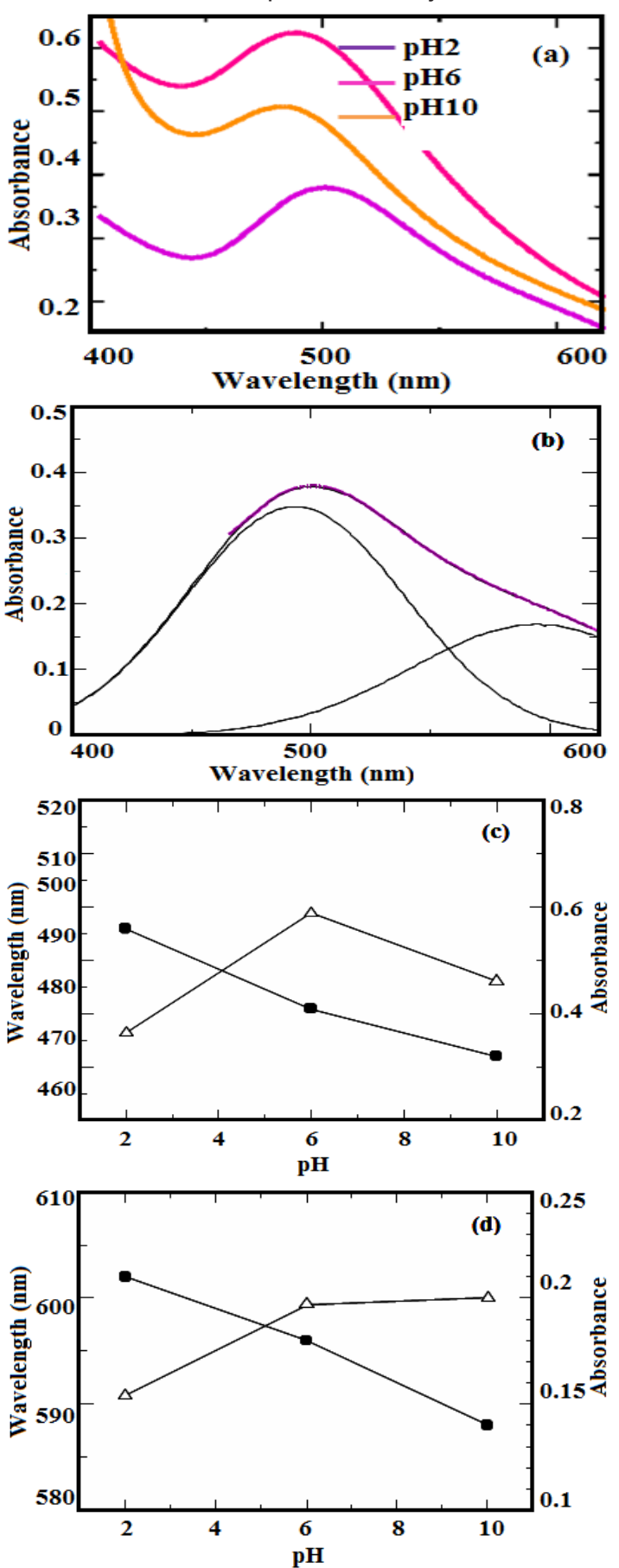

Fig. 2. Au nanoparticles colloidal solution synthesized by extract from binahong leaves at various $\mathrm{pH}\left(\left[\mathrm{AuCl}_{4}-\right]=0.60 \mathrm{mM}\right)(\mathrm{A})$, deconvoluted peak of Au nanoparticles SPR spectrum at pH 2 $(B)$, the relationship between wavelength $(\bullet)$ and absorbance $(\Delta)$ of SPR peak and pH for first peak (C) and second peak (D)
By Gaussian fitting program, deconvolution of the peaks were constructed and the result revealed two overlapped peaks of each SPR spectrum. SPR spectrum at high wavelength correlated with the formation of large and/or nonspherical particles. The difference between the first and second peaks related to the aspect ratio of nonspherical particles. The larger the aspect ratio, the larger the wave peak length in the vertical shift. Fig. 2B revealed that the difference was a significant value at $\mathrm{pH} 2$, thus the formation of nonspherical particles were probably occurred in this $\mathrm{pH}$.

Transmission electron microscopy (TEM) can be used directly to image nanoparticles at scales approaching a single atom ${ }^{28}$ and very useful to provide information of particle size and shape, and their distribution. TEM image of the Au nanoparticles at low pH was shown in Fig. 3. From the TEM image, it can be explained that the particles were in the range of nanosize. Since the metal particles in the samples were only $\mathrm{Au}$, thus the particles have shown by the TEM image (dark images, which means high atomic weight) were only Au particles.

This figure showed that nearly all particles have sized within the range of $25-50 \mathrm{~nm}$ and have shape of triangular, pentagonal and rhombic. This figure showed that almost all particles have size in the range of $25-50 \mathrm{~nm}$ and have shape of triangular, pentagonal and rhombic. Synthesis of gold nanoparticles using Ziziphus zizyphus also resulted the presence of various geometries of particle shape but are dominated by spheres, with size of $51.8 \pm 0.8 \mathrm{~nm}^{29}$. In this recent study, the synthesis technique which produce the large amount of nonspherical Au nanoparticles have an advantage due to the capability of these particles to be applied as contrast agents for fluorescent and optical imaging and ultrasensitive detection for various biomolecules ${ }^{30}$.

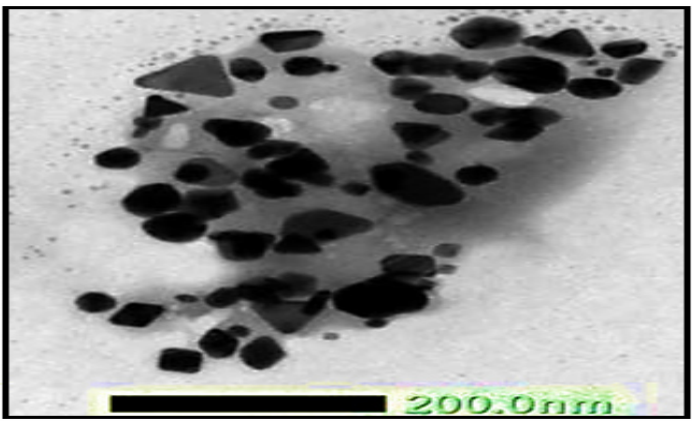

Fig. 3. TEM image of Au nanoparticles synthesized by extract of binahong leaves at $\mathrm{pH} 2$ 


\section{Effect of irradiation power}

The microwave radiation heats up a material through its dielectric loss, which converts the radiation energy into thermal energy. The average power (Pav) dissipated by the material in the microwave field can be expressed in a mathematical expression reported in previous reference, ${ }^{26}$ which explains that the higher the dielectric loss of a material, the higher the energy that can be absorbed. The reference also describe equation which explicitly shows the linear relationship between the penetration depth and the wavelength of applied microwave. If the wavelength (frequency) of the applied field is varied, microwave energy can penetrate a target material with various depths ${ }^{26}$. The frequency of the domestic microwave oven is generally constant, i.e. $2,45 \mathrm{GHz}$, while the intensity (quadratic amplitudo) or irradiation power can be adjusted to a certain value.

The equation discussed above also explained that the higher the irradiation power, the higher the energy that can be transferred to the material. The transferred energy is absorbed by the dielectric substances or ionic species. Both these substances contribute in the heating process of the solution, thus, the increase in transferred energy induced the increase in the temperature of the solution.

Higher temperature of the solution enhances the nucleation rate in the synthesis of nanoparticles, leading to the smaller size, narrower size distribution and more homogeneos of the particle shape. The relation between nucleation rate and temperature can be expressed by equation below,

$R_{N}=\left\{C_{0} k T \mid\left(3 \pi \lambda^{5} \eta\right)\right\} \exp \left(-\Delta G^{*} / k T\right)$

$R_{N}$ is nucleation rate, $C_{o}$ is the number of nucleation centre (in the homogeneous nucleation the value is the same as initial concentration), $\mathrm{k}=$ Boltzman constant, $\mathrm{T}=$ temperature, $\lambda=$ diameter of the growth species, $\eta=$ viscosity, and $\Delta G^{*}=$ critical free energy. Since $C_{0}$ is constant for $A u$ precursor employed in the synthesis, and $k, \eta, \lambda, \pi$ are constant, thus, the higher the temperature, the faster the nucleation rate. Seol et al., ${ }^{31}$ reported the influence of microwave power on the size and its distribution of Au nanoparticles, in which high power capable to reduce the size of particles and facilitate the more homogeneous morphology.

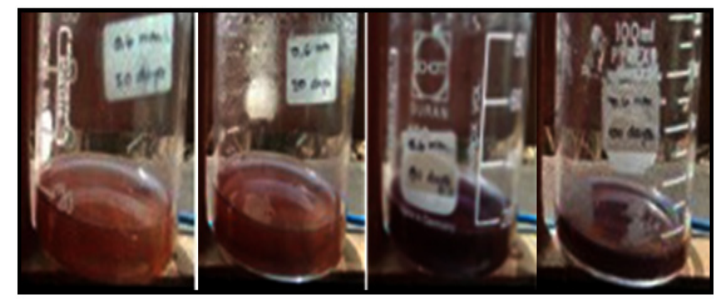

Fig. 4. The colloidal solution of Au nanoparticles synthesized by extract of binahong leaves at various irradiation power $\left(\left[\mathrm{AuCl}_{4}-\right]=0.60 \mathrm{mM}\right)$

The influence of the various irradiation power on the optical characteristic of colloidal Au nanoparticles were shown in Fig. 4. When the irradiation power was increased from $30 \%$ to $100 \%$ of total power of $800 \mathrm{~W}$, the formation rate of characteristic dark red colloidal Au nanoparticles were faster. This phenomenon was observed from the change of solution color from clear to red, even during the irradiation time less than $1 \mathrm{~min}$ for irradiaton power of $80 \%$ of total power. With the same irradiation time, the irradiation power of $80 \%$ and $100 \%$ of total power altering the color of colloidal nanoparticles to become dark violet. This result indicated the significant change in the morphology of particles and/or particle size at high energy.

Figure 5 depicted the change in the wavelength of the SPR peak, showed gaussian curve with the change of irradiation power. The same trend was followed at Au precursor concentration of both $0.40 \mathrm{mM}$ and $0.60 \mathrm{mM}$, though the maximum peak was achieved at different irradiation power.

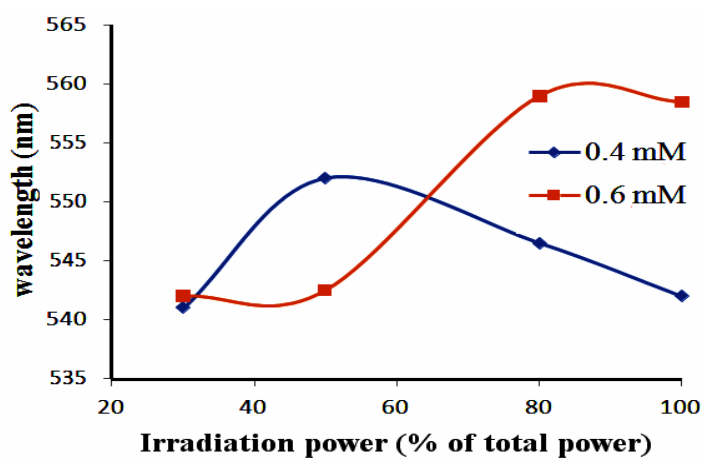

Fig. 5. The relationship between wavelength of SPR peak and irradiation power

Since the higher wavelength related with the larger and/or nonspherical particles, the maximum peak may be indicated as optimum peak, and it was achieved at less irradiation power for $\mathrm{Au}$ precursor of $0.40 \mathrm{mM}$ compared to that of $0.60 \mathrm{mM}$. 
Higher $\mathrm{Au}$ precursor concentration resulted in the higher wavelength at optimum peak, as explained at previous literature ${ }^{19}$. Higher irradiation power clearly dropped the wavelength of SPR peak for lower Au precursor concentration, since it is easier to get smaller and spherical particles when the Au precursor concentration was low and the energy was sufficient to make the high rate of nucleation (Figure 6).

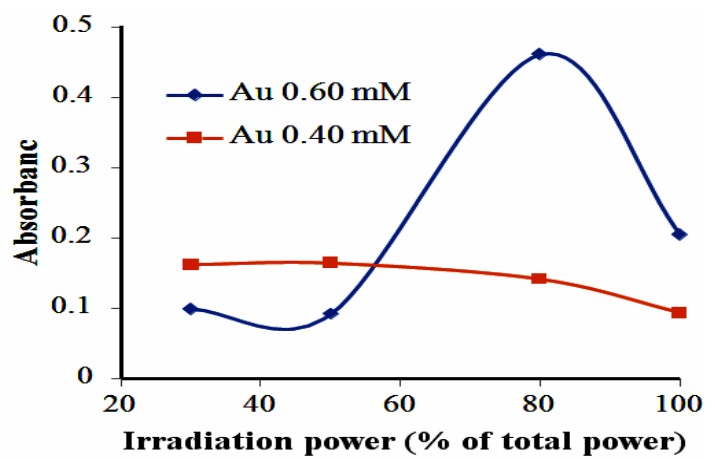

Fig. 6. The relationship between absorbance of SPR peak and irradiation power

Absorbance of the SPR peak was also influenced by the irradiation power (Fig. 6) but the effect was more prominent at Au precursor concentration of $0.60 \mathrm{mM}$. At irradiation power of $80 \%$ the absorbance was high, but the peak was asymmetric, indicating more than one peak contribute to the overall peak. By deconvolution using gaussian fitting program, it revealed that the peak composed of two individual peaks with different wavelength and absorbance (Fig.7). Peak at wavelength of $603 \mathrm{~nm}$ was more dominant compared to that of $541 \mathrm{~nm}$. Similar to the synthesis at low $\mathrm{pH}$, the formation of nonspherical particles were probably occurred in this irradiation power, with larger extent of the formation of this typical of particles. The mechanism of the growth of particles in this condition has not been clear and need to be further examined.

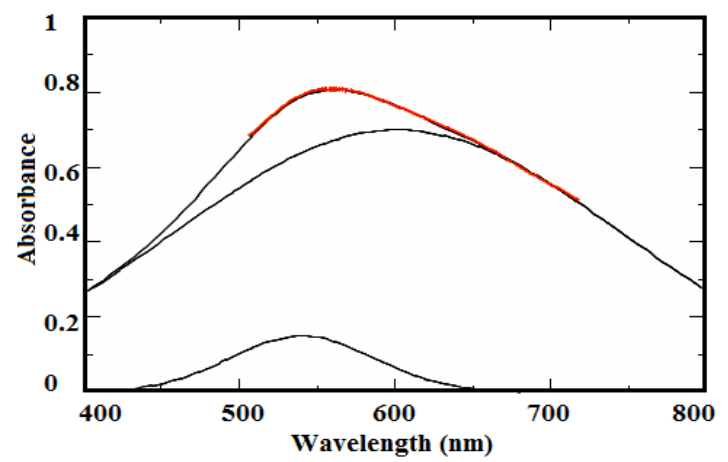

Fig. 7. Deconvoluted peak at irradiation power of $80 \%$ of total power (first wavelength $=541 \mathrm{~nm}$, second wavelength $=603 \mathrm{~nm}$ )

\section{Effect of irradiation time}

In order to study the effect of irradiation time on the Au nanoparticles nucleation and growth, the synthesis of $\mathrm{Au}$ nanoparticles was conducted at various irradiation time, in the range of 30-120 second. The results confirmed that the longer the irradiation time, the higher the absorbance of the SPR peaks, indicated that the reduction process was continued to form Au nanoparticles, leading to larger amount of these particles.

Even though the peaks were concentric, maximum wavelength of each peak were not same for each irradiation time. The longer the irradiation time, the larger the red-shift of the peak until $90 \mathrm{~min}$ of irradiation. After $90 \mathrm{~min}$ the wavelength was blueshifted to $551 \mathrm{~nm}$ (Fig. 8). Since the wavelength was shifted to different value at different time, the linear relationship between absorbance and concentration could not be applied in this case. The different wavelength related with the different nucleation and growth of the particles, thus, despite the increased concentration resulted in the increase of absorbance, the relationship may not linear.

According to Wuitschick et al., 32 mechanism of the formation of Au nanoparticles by Turkevich method consisted of four steps: partial reduction of the gold precursor and the formation of small clusters from the Au monomers, formation seed particles with small radii, reduction of the ionic gold whereby the generated gold monomers grow on top of the seed particles' surfaces until the precursor is fully consumed. No further particles are formed during the last step, thus the longer time of synthesis providing opportunity for particles to grow up until it reaches an optimum size.

In this study, the reducing agent is a large biomolecule which also acts as capping agent for metal salt precursor. After reduction process of the metal salt precursor, yielding a zero valent metal nanoparticles, the bulky structure of this biomolecule remains around the surface of the as-formed nanoparticles. The longer the irradiation time, the larger amount of particles will be formed. Coalescence between particles may occur, resulting larger size of particles. However, the growth of the particles were limited by the bulky structure of capping agent which enveloping the surface of particles. Thus, the wavelength was not drastically shifted to much longer wavelength (Figure 8). 


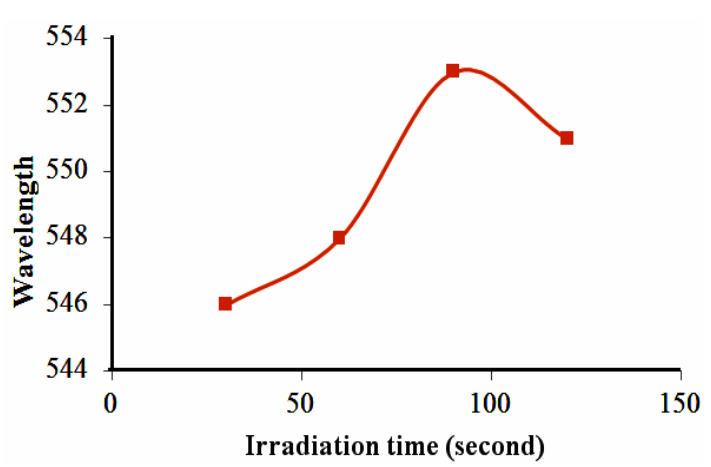

Fig. 8. The relationship between wavelength of SPR peak and irradiation time

CONCLUSION

The experimental results showed that the formation of $\mathrm{Au}$ nanoparticles were succesfully proceed via one step synthesis using natural, low-cost, environmentally friendly source, i.e. extract of binahong (Anredera cordifolia) leaves. Several factors such as $\mathrm{pH}$, irradiation power and time significantly influenced the morphology of the as-formed particles. At low $\mathrm{pH}$, the nonspherical particle was more commonly formed. The higher the $\mathrm{pH}$, the stabilization of particles took place more effectively. UV-Vis spectra also indicated that both microwave irradiation power and time significantly affect both the size and shape of particles. Effect of the irradiation power was more pronounced for higher concentration Au precursor. These results of various experimental condition may give advantageous information in designing synthesis of Au nanoparticle in larger production scale.

\section{ACKOWLEDGEMENT}

AKA Bogor Polytechnic as a place to do research and assistance cost has been given with the Decree Director Polytechnic of AKA Bogor Number 101 / Poltek AKA / Kep /7/ 2019 concerning the Establishment of a Research Team at the Polytechnic of AKA Bogor for the 2019 Budget.

\section{Conflict of interest}

The authors declare no conflicts of interest.

\section{REFERENCES}

1. Yan, Y.; Pillai, P.P.; Timonen, J.V.I.; Emami, F.S.; Vahid, A. \& Grzybowski, B.A., Synthesis of Toroidal Gold Nanoparticles Assisted by Soft Templates, Langmuir., 2014, 30(33), 9886- 9890.

2. Joo, J.H.; Kim, B.H. \& Lee, J.S.; Synthesis of Gold Nanoparticle-Embedded Silver Cubic Mesh Nanostructures Using AgCI Nanocubes for Plasmonic Photocatalysis, Small., 2017, 13(43), 43.

3. Jenkins, J.A.; Wax, T.J. \& Zhao, J.; Seed Mediated Synthesis of Gold Nanoparticles of Controlled Sizes to Demonstrate The Impact of Size on Optical Properties. J. Chem Educ., 2017, 94, 1090-1093.

4. Peng, H.C.; Li, Z.; Aldahondo, G.; Huang, H. \& Xia.Y.; Seed Mediated Synthesis of Pd Nano Crystal: The Effect of Surface Capping on The Heterogeneous Nucleation and Growth. The J. Phys. Chem., 2016, 120.11754-11761.

5. Shang, Y.; Min, C., Hu, J.; Wang, T.; Liu, H. \& Hu, Y.; Synthesis of gold nanoparticles by reduction of $\mathrm{HAuCl}_{4}$ under UV-irradiation. Solid State Sci., 2013, 15, 17-23.

6. Barbosa, H.F.P.; Neumann, M.G. \& Cavalheiro, C.C.S., Photochemical Synthesis of Gold Nanoparticles by Irradiation of Gold Chloride with the $2^{\text {nd }}$ Harmonic of a Nd: YAG Laser, J.
Braz. Chem. Soc., 2019, 30(4), 813-818.

7. Grewal, A.S.; Kumar, K.; Redhu, S. \& Bhardwaj, S.; Microwave Assisted Synthesis: A Green Chemistry Approach International Research. J. Pharm. Appl. Sci. (IRJPAS)., 2013, 3, 278- 285.

8. Normanbhay, S. \& Ong, M.Y., A Review of Microwave Assisted Reactions for Biodiesel Production. J. Bioengineering., 2017, 4(2), 1-23.

9. Saif, S.; Tahir, A. \& Chen, Y.; Green Synthesis of Iron Nanoparticles and Their Environmental Applications and Implication, Nanomaterials., 2016, 6(11), 1-26.

10. Iravani, S.; Korbekandi, H.; Mimohammadi, S.V. \& Zulfaghari, B.; Synthesis of Silver Nanoparticles: Chemical, Physical and Biological Methods. Res. Pharm. Sci., 2014, 9(6), 385-406.

11. Teimuri M.R.; Hadi, R.; Tahmasebi, B.; Farhoudian, S.; Mahravar, M. \& Nasin, R., Green Synthesis of Gold Nanoparticles using Plant Extract : Mini Review, Nanochem. Res., 2017, 2(1), 8-19.

12. Jafarizad, A.; Safaee, K.; Gharibian, S.; Omidi, Y. \& Ekinci, D., Biosynthesis and In-vitro Study of Gold Nanoparticles Using Mentha and Pelargonium Extracts, Procedia Mater. Sci., 2015, 11, 224-230. 
13. Yu, J.; Xu, D.; Guan, H.N.; Wang, C.; Huang, L.K. \& Chi, D.F.; Facile one-step green synthesis of gold nanoparticles using Citrus maxima aqueous extracts and its catalytic activity. Materials Lett., 2016, 166, 110-112.

14. Singh, P.; Pandit, S.; Garnæs, J.; Tunjic, S.; Mokkapati, V.R.; Sultan, A.; Thygesen, A.; Mackevica, A.; Mateiu, R.V.; Daugaard, A.E.; Baun, A. \& Mijakovic, Green synthesis of gold and silver nanoparticles from Cannabis sativa (industrial hemp) and their capacity for biofilm inhibition. Int. J. Nanomedicine., 2018, 13, 3571-3591.

15. Folorunso, A.; Akintelu, S.; Oyebamiji, A.K.; Ajayi, S.; Abiola, B.; Abdusalam, I. \& Morakinyo, A.; Biosynthesis, characterization and antimicrobial activity of gold nanoparticles from leaf extracts of Annona muricata, J. Nanostruct. Chem., 2019, 9(2), 111-117.

16. Gopalakrishnan, R. \& Raghu, K., Biosynthesis and characterization of gold and silver nanoparticles using milk thistle (Silybum marianum) seed extract, J. Nanosci., 2014 (905404), 1-8.

17. Isaac, R.S.R.; Sakthivel, G. \& Murthy, Ch., Green synthesis nanoparticles using Averrhoa bilimbi fruit extract. J. Nanosci., 2013, (906592), 1-6.

18. Selawa, W.; Revolta, M.; Runtuwene, J. \& Citraningtyas, G.; Kandungan flavonoid dan kapasitas antioksidan total ekstrak etanol daun binahong (Anredera cordifolia). Pharmacon Jurnal IImiah Farmasi., 2013, 2(1), 2302-2493.

19. Foliatini \& Nurdiani, Biosynthesis of anisotropic nanogold using binahong (Anredera cordifolia) leaves extract as a morphology controlling agent, Int. J. Chem. Studies., 2018, 6(2), 1150-1157.

20. Thanh, N.T.K.; Maclean, N. \& Mahiddine, S., Mechanism of Nucleation and Growth of Nanoparticles in Solution. Chem. Rev., 2014, 114(15), 7610-7630.

21. Choi, S.I. \& Kim, J.H., Radiation-Induced Discolation and Growth Behaviour of Zirconium and Zirconium 2 Alloys - A Review, Nucl. Eng. Technol., 2013, 45(3), 385-392.

22. Contreras T. B.; Díaz G. V.; GuzmánG. E.; Sanhueza, I.; Coelho, P.; Godoy, S.E.;Torres, S. \& Oyarzún, P., Slight pH Fluctuations in the Gold Nanoparticle Synthesis Process Influence the Performance of the Citrate Reduction Method, Sensors., 2018, 18, 22462254.
23. Fernando, I.; Zhou, Y.; Impact of $\mathrm{pH}$ on the stability, dissolution and aggregation kinetics of silver nanoparticles, Chemosphere., 2019, 216, 297-305.

24. Madkour L.H, Applications of gold nanoparticles in medicine and therapy, Pharm Pharmacol Int J., 2018, 6(3):157-174, DOI: 10.15406/ppij.2018.06.00172.

25. Khlebtsov, N.; Bogatyrev, V.; Dykman, L.; Khlebtsov, B.; Staroverov, S.; Shirokov, A.; Matora, L.; Khanadeev, V.; Pylaev, T.; Tsyganova, N. \& Terentyuk, G., Analytical and Theranostic Applications of Gold Nanoparticles and Multifunctional Nanocomposites, Theranostic., 2013, 3(3), 67-180.

26. Foliatini, Yulizar, Y. \& Hafizah, M.A.E., Microwave-assisted Synthesis of Alginate Stabilized-Gold Nanoparticle, Makara J. Sci., 2014, 18(4), 111-118.

27. Jiang, H.; Moon, K.-S.; Zhang, Z.; Pothukuchi, S. \& Wong, C.P., Variable frequency microwave synthesis of silver nanoparticles, J. Nanoparticle Res., 2006, 8, 17-124.

28. Pyrz, W.D. \& Buttrey, D.J., Particle Size Determination Using TEM: A Discussion of Image Acquisition and Analysis for the Novice Microscopist, Langmuir., 2008, 24(20), 11350-11360.

29. Aljabali, A.A.A.; Akkam, Y.; Al Zoubi, M.S.; Al-Batayneh, K.M.; Al-Trad, B.; Alrob, O.A.; Alkilany, A.M.; Benamara, M. \& Evans, D.J.; Synthesis of Gold Nanoparticles Using Leaf Extract of Ziziphus zizyphus and their Antimicrobial Activity, Nanomaterial (Basel)., 2018, 8(3), 174.

30. Wagner, O.; Schultz, M.; Edri, E.; Meir, R.; Barnoy, E.; Meiri, A.; Shpaisman, H.; Sloutskin, E. \& Zalevsky, Z.; Imaging of nanoparticle dynamics in live and apoptotic cells using temporally- modulated polarization. Sci. Rep., 2019, 9(1650), doi:10.1038/ s41598-018-38375-9.

31. Seung K.S, Daeho K.; Sunshin J.; Yeukuang $\mathrm{H}$, Microwave synthesis of gold nanoparticles: Effect of applied microwave power and solution $\mathrm{pH}$, Materials Chemistry and Physics., 2011, 131(s 1-2), 331-335, DOI: 10.1016/j.matchemphys.2011.09.050.

32. Wuithschick, M.; Birnbaum, A.; Witte, S.; Sztucki, M. \& Vainio, U.; Turkevich in New Robes: Key Questions Answered for the Most Common Gold Nanoparticle Synthesis. ACS Nano., 2015, 9(7), 7052-7071. 